\title{
Development of a High-Performance MALDI-TOF Mass Spectrometer Utilizing a Spiral Ion Trajectory
}

\author{
Takaya Satoh, Takafumi Sato, and Jun Tamura \\ JEOL Ltd., Tokyo, Japan
}

\begin{abstract}
A novel MALDI-TOF mass spectrometer that utilizes a spiral ion trajectory was developed. In this mass spectrometer, the ions sequentially passed through four toroidal electrostatic sectors and revolved along a figure-eight-shaped orbit on a particular projection plane. Each toroidal electrostatic sector had eight stories, and during multiple revolutions, the ion trajectory shifted perpendicular to the projection plane in every cycle, thereby generating a spiral trajectory. The flight path length of one cycle was $2.1 \mathrm{~m}$; therefore, when the ions completed eight cycles, the total flight path length was $17 \mathrm{~m}$. By adopting an ion optical system that had a flight path length five times longer than that in the commonly used reflectron ion optical system, the mass dependence on the mass resolving power was reduced, while improving the mass accuracy of the mass measurements. The basic performance of the system was tested by using standard peptides or the tryptic digest of bovine serum albumin. A mass resolving power of 80,000 (full width at half maximum) was achieved at $\mathrm{m} / \mathrm{z}=2564$ (ACTH18-39). An improved mass accuracy less than $2 \mathrm{ppm}$ was realized over a wide $\mathrm{m} / \mathrm{z}$ range of 500 to 3000 by correction using one or two internal standard substances. (J Am Soc Mass Spectrom 2007, 18, 1318-1323) (c) 2007 American Society for Mass Spectrometry
\end{abstract}

$\mathrm{T}$ he invention of the delayed extraction technique $[1,2]$ dramatically improved the matrixassisted laser desorption/ionization (MALDI) $[3,4]$ time-of-flight (TOF) [5, 6] mass spectrometer. However, a narrow effective $m / z$ range was obtained due an intrinsic feature of the ionization mechanism. In MALDI, ions and neutral particles gain similar velocities in the plume [7]. The average velocity weakly depends on the mass value so that the initial kinetic energy increases proportionally with the mass value. This leads to the $\mathrm{m} / \mathrm{z}$ dependence of the location of the time-of-flight focal point. This in turn causes the mass resolving power to depend on the mass and reduces the mass accuracy.

To improve the MALDI-TOF mass spectrometer further, it is necessary to raise the level of the mass resolving power and the mass accuracy by reducing the mass dependency of the delayed extraction technique. The reflectron ion optical system of the MALDI-TOF mass spectrometer comprises two systems connected in tandem. One system focuses the initial kinetic energy distribution by using the delayed extraction technique at a particular focal point; the other focuses on the kinetic distribution of the focal point on the detection surface. In the typical MALDI-TOF, the flight path lengths of the former and latter systems are of the order of $L 1=0.3 \mathrm{~m}$ and

Address reprint requests to Dr. Takaya Satoh, JEOL Ltd., 3-1-2 Musashino, Akishima 196-8558, Tokyo, Japan. E-mail: taksatoh@jeol.co.jp
$L 2=2$ to $3 \mathrm{~m}$, respectively. To satisfy the requirements for improvement, an extension of the total flight path length as well as a reduction in the $L 1 / L 2$ value are required. In this study, we adopted an ion optical system that employs a spiral ion trajectory [8, 9] instead of the ion mirror. This system is based on a multi-turn ion optical system that uses electrostatic sectors [10-15], particularly the "MULTUM II" system developed at Osaka University [14, 15]. This study focuses on the evaluation of the basic performance of the instrument, such as the mass resolving power, mass accuracy, and sensitivity in applications such as peptide mass fingerprinting.

\section{Experimental}

\section{Instrument}

The spiral ion optical system, which comprised four toroidal electrostatic sectors (TESs), is described in detail in ref [8]. The manner in which the present design differs from that described in ref [8]. is described below. The spiral ion optical system is schematically represented in Figure 1. TES1 shows a TES with the outer electrodes dismantled so as to facilitate the understanding of the alignment of the Matsuda plates [16]. The figure-eight orbit was magnified by a factor of 1.6 and the number of levels was reduced to eight from of the number in the system described in ref [8]. The deflection angle, radius of the ion trajectory, and gap between 


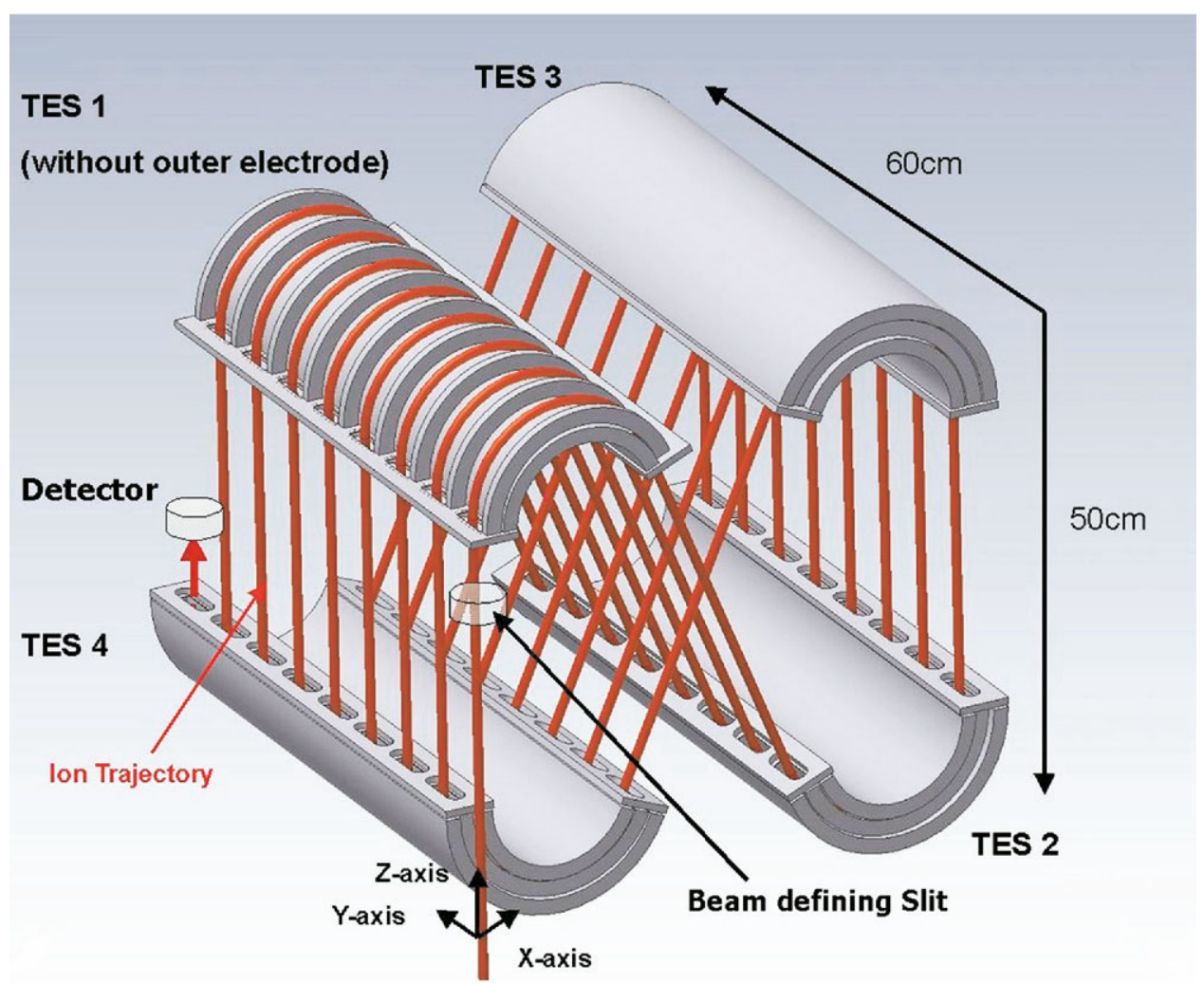

Figure 1. Schematic of the ion optical system utilizing a spiral ion trajectory. The configuration of the four toroidal electrostatic sectors is shown along with beam defining slit, detector, and spiral ion trajectory.

the inner and outer electrodes of the TES were $157.10^{\circ}$, $80 \mathrm{~mm}$, and $16 \mathrm{~mm}$, respectively. The Matsuda plates had a thickness of $8 \mathrm{~mm}$ and were placed $58.3 \mathrm{~mm}$ apart along the Y-axis. The potentials of the inner electrode, outer electrode, and Matsuda plates were set at -4.0 $\mathrm{kV},+4.0 \mathrm{kV}$, and $+0.85 \mathrm{kV}$, respectively. The ions traveled for $2.093 \mathrm{~m}$ along the orbital surface and shifted downward by $58.3 \mathrm{~mm}$ in each cycle; therefore, the desirable slope angle in the toroidal electrostatic field was $\tan ^{-1}(58.3 / 2093)=1.6^{\circ}$. Each TES had eight levels and the flight path length of each cycle was 2.093 $\mathrm{m}$; consequently, the total flight path length became $\sim 17 \mathrm{~m}$. The spatial distributions of the TESs were limited to $1 \mathrm{~mm}$ and $2 \mathrm{~mm}$ along the X-and Y-axis, respectively, by a beam-defining slit placed in front of the first level of TES1. The pressure in the analyzer housing was maintained below $2.0 \times 10^{-5} \mathrm{~Pa}$. We used a secondary electron multiplier ion detector: DM167 (ETP, Ermington, Australia). An 8-bit digitizer DP211 with a memory option of $4 \mathrm{M}$ points (Acqiris, Geneva, Switzerland) was used for data acquisition.

Figure $^{\circ} 2^{\circ}$ shows $^{\circ}$ the ${ }^{\circ}$ configuration ${ }^{\circ}$ of $^{\circ}$ the $^{\circ}$ ion ${ }^{\circ}$ source. The Z-axis was tilted by $1.6^{\circ}$ toward the Y-axis so that the ion packets could travel toward the first story of TES1 without deflection. A pulsed laser beam with a wavelength of $337 \mathrm{~nm}$ that was generated by a nitrogen laser MNL-103LD (Lasertechnik Berlin GmbH, Berlin, Germany) was directed by three mirrors (two of which were TFA-20C05-4, Sigma Koki Co., Ltd., Tokyo, Japan, and the third was 45,602-D, Edmund Optics, Barrington, NJ) and one focusing plane-convex lens (SLSQ-

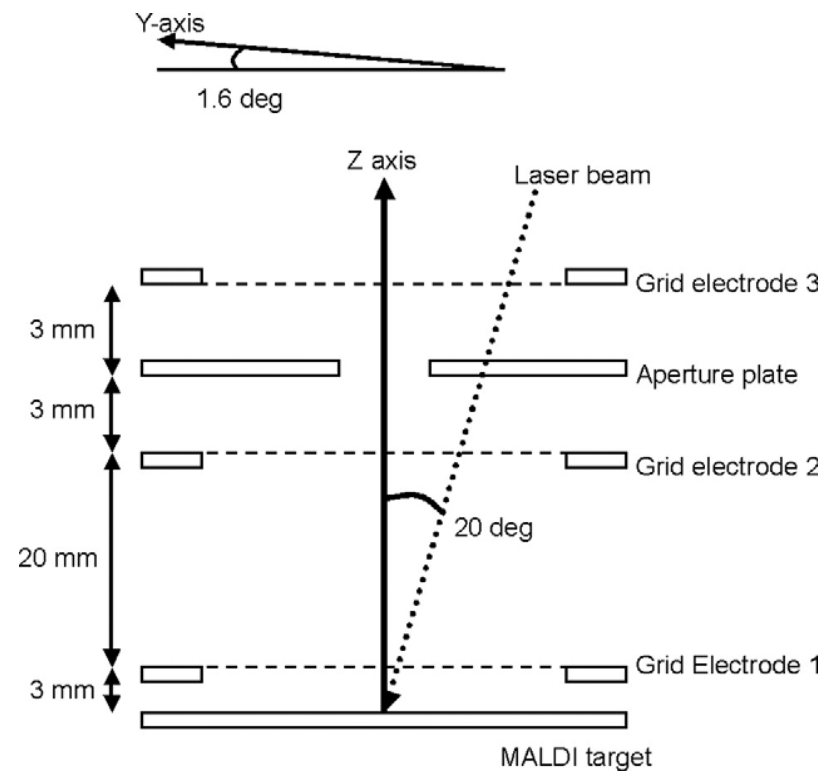

Figure 2. Schematic of the ion source. This diagram includes acceleration region comprising of MALDI target and grid electrodes 1 and 2 and the Einzel lens system comprising the aperture electrode and grid electrodes 2 and 3. 


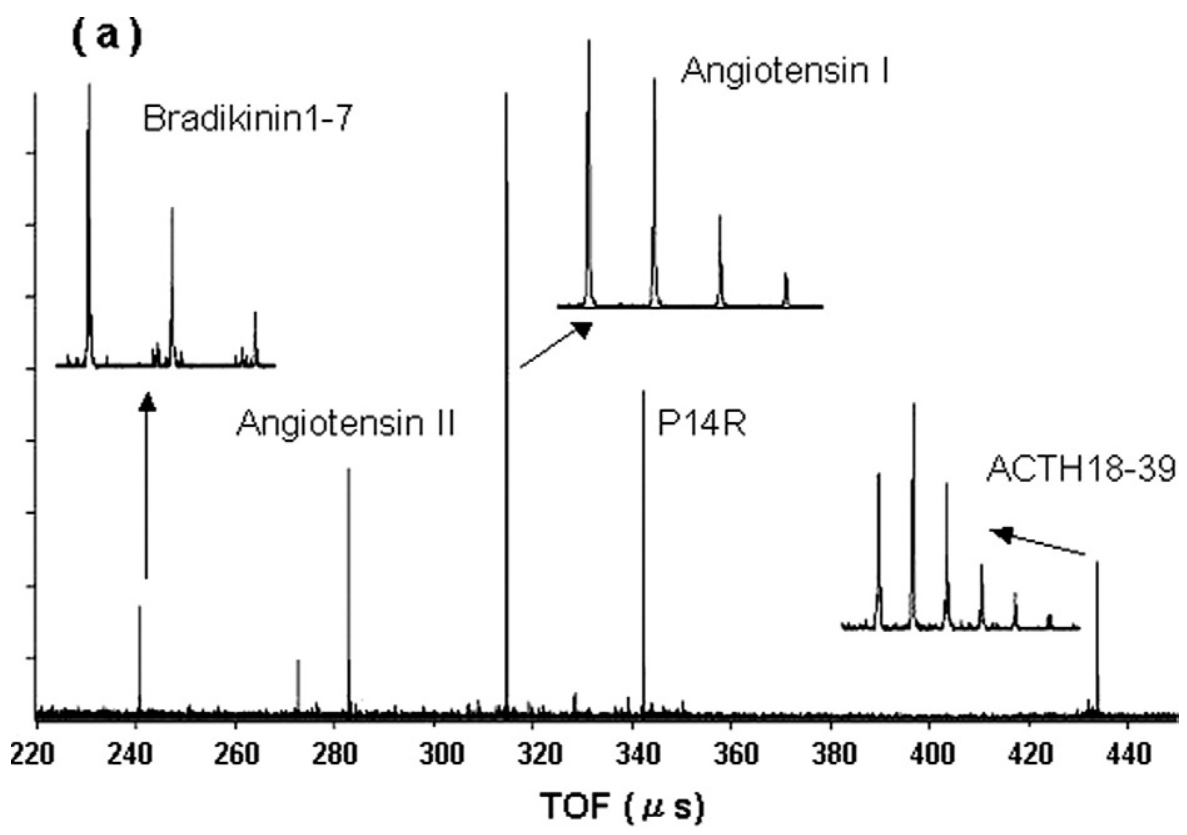

(b)

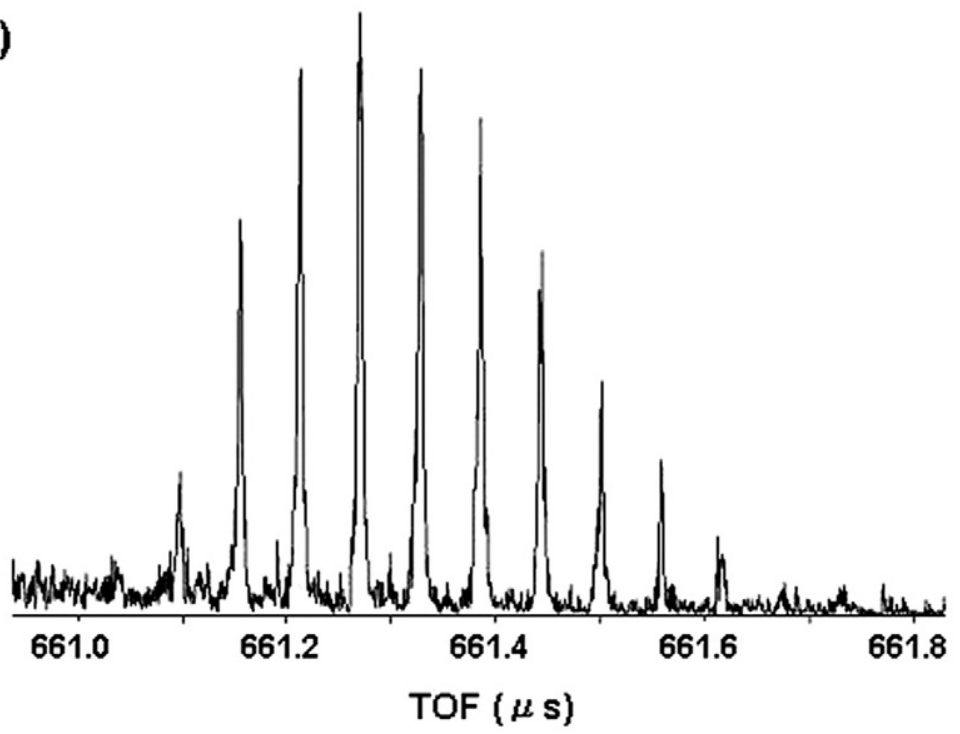

Figure 3. Typical TOF spectra of (a) mixture of five standard peptides and (b) insulin, using $\alpha$-CHCA and sinapic acid as matrices, respectively. The TOF ranges around bradykinin 1 to 9 , angiotensin I, and ACTH18-39 are enlarged.

20-200P, Sigma Koki Co., Ltd.). The beam then irradiated the MALDI target at an angle of $20^{\circ}$. The laser intensity was adjusted by a neutral density filter (VND50U, Sigma Koki Co., Ltd.). The ions produced were accelerated through the acceleration region comprising the MALDI target, grid electrode 1, and grid electrode 2. A static voltage of $+20 \mathrm{kV}$ and a pulse voltage of -3 $\mathrm{kV}$ superimposed on it were applied to the MALDI target and grid electrode 1, respectively. Grid electrode 2 was connected to ground. After acceleration, the ion packets were collimated by the Einzel lens system, which comprised grid electrode 2, an aperture plate having a hole with a diameter of $3 \mathrm{~mm}$, and grid electrode 3. A static voltage of $1.5 \mathrm{kV}$ was applied to the aperture plate, and grid electrode 3 was connected to ground. The internal generator of the laser triggered its firing. The optical trigger signal was generated by the laser and used to synchronize the laser firing with the rest of the setup. The delay generator allowed us to adjust the timing between the laser firing and the start of the time-of-flight measurement in $5 \mathrm{~ns}$ increments. The minimal delay was limited to $200 \mathrm{~ns}$ due to the combined effect of the propagation delays in the setup. The "delay time", mentioned hereinafter, represents the time delay of the delay generator itself. The high voltage pulse on grid electrode 1 was also switched on at the start of the time-of-flight measurement. 


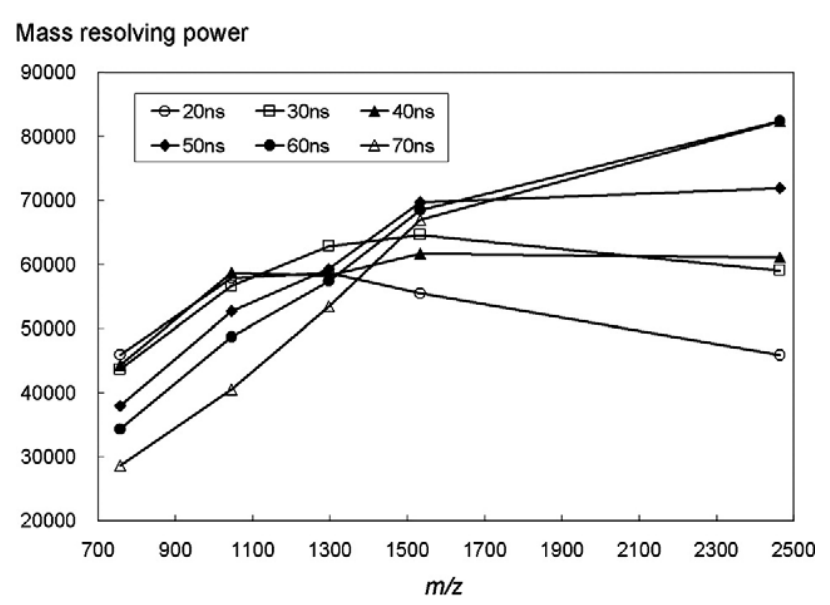

Figure 4. The variation in mass resolving power (FWHM) of five standard peptides by changing the delay time from 20 to $70 \mathrm{~ns}$.

\section{Samples and Preparations}

Bradykinin1-9, angiotensin II, angiotensin I, P14R, neurotensin, ACTH18-39, insulin, and poly(propylene glycol)s were purchased from Sigma Aldrich Co. (St. Louis, $\mathrm{MO})$. A tryptic digest of BSA was purchased from Yamato Scientific Co., Ltd. (Tokyo, Japan). The matrix compounds- $\alpha$-cyano-4-hydroxycinnamic acid $(\alpha-$ CHCA) and sinapic acid were purchased from Wako Pure Chemical Industries, Ltd. (Osaka, Japan). Acetonitrile (ACN) and trifluoroacetic acid (TFA) were also purchased from Wako.

The matrix compounds were dissolved in 1:1 ACN/ $0.1 \%$ TFA deionized water solution at a concentration of $10 \mathrm{mg} / \mathrm{mL}$. The $\alpha$-CHCA solution was diluted four times in the same solvent for measuring the tryptic digest of BSA at a concentration of $10 \mathrm{fmol} / \mu \mathrm{L}$. The standard peptide mixture was prepared by diluting bradykinin1-9, angiotensin II, angiotensin I, P14R, and ACTH18-39 in 0.1\% TFA deionized water solution at concentrations of $0.5,0.25,0.5,0.25$, and $1 \mathrm{pmol} / \mu \mathrm{L}$, respectively. The tryptic digest of BSA was dissolved in deionized water to produce a final concentration of $0.2-100 \mathrm{fmol} / \mu \mathrm{L}$. The matrix and analyte solutions were mixed in the ratio of $1: 1(\mathrm{vol} / \mathrm{vol})$, and $1 \mu \mathrm{L}$ of the mixture was deposited on a MALDI sample plate made of stainless steel by the dried-droplet method.

\section{Results and Discussion}

\section{Mass Resolving Power}

Figure $3 a^{\circ}$ shows ${ }^{\circ} a^{9}$ typical ${ }^{1} \mathrm{TOF}^{\circ}$ spectrum ${ }^{\circ} f^{\circ}{ }^{\circ}$ mixture ${ }^{\circ}$ of five standard peptides with a delay time of 40 ns: bradykinin1-9 (MW 756.4), angiotensin II (MW 1045.5), angiotensin I (MW 1296.5), P14R (MW 1532.9), and ACTH18-39 (MW 2464.2). The protonated molecules [M $+\mathrm{H}]^{+}$of these peptides were observed. The TOF ranges around bradykinin1-9 (MW 756.4), angiotensin I, and ACTH18-39 are enlarged. The mass resolving power in these ranges is discussed later. We also performed measurements for a larger molecule such as insulin (MW 5729.6) whose typical mass spectrum is shown in Figure $3 \mathrm{~b} .{ }^{\circ} \mathrm{A}^{\circ} \mathrm{mass}^{\circ}{ }^{\circ}$ esolving ${ }^{\circ}$ power $^{\circ}$ greater ${ }^{\circ}$ than $^{\circ} 60,000$ yielded a well-defined isotopic pattern.

The variations in the mass resolving power (FWHM) of the five peptide peaks with changes in the delay time are $^{\circ}$ shown ${ }^{\circ}$ in $^{\circ}{ }^{\circ} i g u r e^{\circ} 4 .{ }^{\circ}$ Each $^{\circ}$ point $^{\circ}{ }^{\circ}$ epresents ${ }^{\circ}$ the ${ }^{\circ}$ mean value of twenty measurements. The optimal delay time was different at each $\mathrm{m} / \mathrm{z}$ value: an improved resolving power was obtained with a shorter delay at an $\mathrm{m} / \mathrm{z}$ value of around 750; however, this was not the case at around 2450 . The present data agrees with the results reported ${ }^{\circ} \mathrm{by}^{\circ} \mathrm{Brown}^{\circ}$ and $^{\circ}$ Lennon $[1]$.

\section{Mass Accuracy}

The mass accuracy was evaluated using poly(propylene glycol)s. Before the measurement, a calibration equation relating the TOF and the $\mathrm{m} / \mathrm{z}$ value should be determined. We attempted to use the following polynomial equation for calibration with terms up to the fourth order by fitting the measured TOF of 37 peaks to their theoretical $\mathrm{m} / \mathrm{z}$ values. This equation is given as follows:

$$
\sqrt{m / z}=a+b t+c t^{2}+d t^{3}+e t^{4}
$$

where $a, b, c, d$, and $e$ are the constants and $t$ is the TOF. The order of the calibration equation can be selected; for example, only four constants, $a-d$, need to be determined for the equation if terms up to the third order are considered. The $\mathrm{m} / \mathrm{z}$ deviations between the theoretical $\mathrm{m} / \mathrm{z}$ values and calibrated $\mathrm{m} / \mathrm{z}$ values in terms of the root mean $^{\circ}$ square $^{\circ}(\mathrm{rms})^{\circ}$ values $^{\circ}$ are $^{\circ}$ listed $^{\circ}$ in $^{\circ}$ Table $^{\circ} 1 .^{\circ}$ When using the calibration equation with two terms up to the first-order, the mass accuracy is slightly less than that in the other cases. However, an improved mass accuracy greater than $1.0 \mathrm{ppm}(\mathrm{rms})$ is observed when the order of the calibration equation is greater than 2 .

A difference in the mass accuracy was observed when calibration equations with terms up to the first and second orders were used. Twenty mass spectra were acquired, and the constants of the polynomial equations were determined for each spectrum. The rms values of the difference between the theoretical and calibrated $\mathrm{m} / \mathrm{z}$ values of 37 peaks were calculated; these values $^{\circ}$ are $^{\circ}$ shown $^{\circ}$ in $^{\circ}$ Figure $^{\circ} 5 .^{\circ} \mathrm{A}^{\circ}$ systematic $^{\circ}$ error, convex upward, was observed when the first-order calibration equation was used. This was due to the $\mathrm{m} / \mathrm{z}$ dependency that originated from the delayed extraction technique; however, the deviation was relatively

Table 1. Comparison between the theoretical and calibrated $\mathrm{m} / \mathrm{z}$ values in terms of the root mean square $(\mathrm{rms})$ values of 37 peaks using different numbers of terms up to the fourth order for the calibration equations

\begin{tabular}{ccccc}
\hline Order & 1st & 2nd & 3rd & 4th \\
\hline \hline rms & $1.15 \mathrm{ppm}$ & $0.83 \mathrm{ppm}$ & $0.83 \mathrm{ppm}$ & $0.76 \mathrm{ppm}$ \\
\hline
\end{tabular}




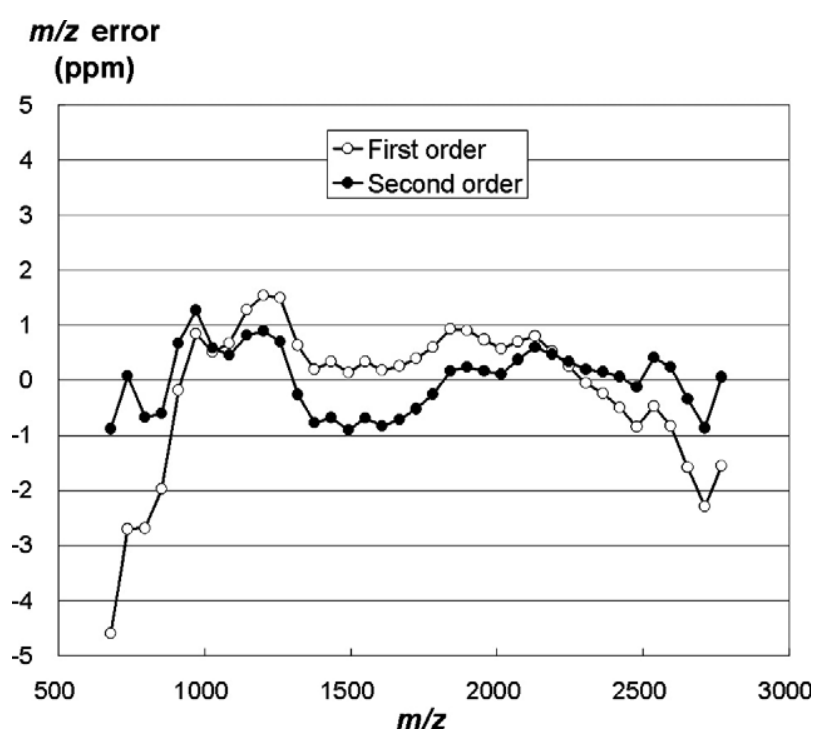

Figure 5. $m / z$ deviation from theoretical value when using firstand second-order equations for calibration.

small—within \pm 5 ppm. Additionally, an improved systematic error of lesser than \pm 1 ppm was observed when the second-order calibration equation was used.

In practical measurements, a temporal drift of the $\mathrm{m} / \mathrm{z}$ values inevitably occurs along with the thermal expansion of the flight tube, fluctuation in the electric power supply due to thermal instability, and undulation of the MALDI target surface. Typically, this drift is about a few dozen of ppm so that it is not negligibly small for precise mass measurements. It is preferable to use an internal standard for compensating this drift. We estimated the mass accuracy by using one and two internal standards. The twenty mass spectra acquired previously were used. The three constants $a, b$, and $c$ for the second-order equation were determined using the mass spectra acquired first. In the case of the compensation performed using one internal standard, the remaining nineteen mass spectra were calibrated by varying $b$ and fixing $a$ and $c$ to match the pivoting point to their theoretical $\mathrm{m} / \mathrm{z}$ values: 1724.2144 . When two internal standards were used, the two pivoting points were
Table 2. Search conditions and results of protein identification by peptide mass fingerprinting using MASCOT

\begin{tabular}{|c|c|c|c|}
\hline \multicolumn{2}{|c|}{ Database } & \multicolumn{2}{|c|}{ NBCInr } \\
\hline \multicolumn{4}{|c|}{$\begin{array}{r}\text { Trypsin } \\
\text { Allowed up to } 1 \text { missed cleavage }\end{array}$} \\
\hline $\begin{array}{l}\text { Fixed mo } \\
\text { Variable } \\
\text { Peptide t } \\
\text { Mass valu }\end{array}$ & $\begin{array}{l}\text { ication } \\
\text { dification }\end{array}$ & $\begin{array}{l}\text { Carboxy } \\
\text { Oxidatic } \\
\pm 20 \mathrm{ppr} \\
\mathrm{MH}^{+}(\mathrm{m}\end{array}$ & $\begin{array}{l}\text { ethyl (C) } \\
\text { (M) } \\
\text { oisotopic) }\end{array}$ \\
\hline $\begin{array}{l}\text { Amount } \\
(\mathrm{fmol})\end{array}$ & $\begin{array}{l}\text { Number of peptides } \\
\text { matched/searched }\end{array}$ & $\begin{array}{c}\text { Sequence } \\
\text { coverage } \\
(\%)\end{array}$ & $\begin{array}{l}\text { MASCOT } \\
\text { score }\end{array}$ \\
\hline 50 & $52 / 81$ & 75 & 570 \\
\hline 10 & $41 / 79$ & 64 & 390 \\
\hline 5 & $36 / 77$ & 54 & 351 \\
\hline 1 & $28 / 57$ & 43 & 255 \\
\hline 0.5 & $31 / 52$ & 46 & 306 \\
\hline 0.1 & $12 / 34$ & 18 & 92 \\
\hline
\end{tabular}

made to coincide with their theoretical $\mathrm{m} / \mathrm{z}$ values, 911.6823 and 2420.7168 , by varying $a$ and $b$ and fixing $c$. The average and rms values of the mass deviation among the 37 different masses, where the deviation at each mass was the mean value observed in the nineteen mass spectra, were $-0.35 \mathrm{ppm}$ and $0.65 \mathrm{ppm}$ for onepoint compensation and $0.38 \mathrm{ppm}$ and $0.79 \mathrm{ppm}$ for two-point compensation, respectively.

\section{Sensitivity}

The sensitivity of the system was tested by measuring 0.1 to $50 \mathrm{fmol}$ of tryptic digest of BSA spotted on the MALDI plate. A typical mass spectrum obtained by measuring ${ }^{\circ}$ the ${ }^{\circ} 0.5^{\circ} \mathrm{fmol}^{\circ}$ spot $^{\circ}$ is $^{\circ}$ shown $^{\circ}$ in ${ }^{\circ}$ Figure $^{\circ} 6 .^{\circ}$ The $\operatorname{MASCOT}^{\circ}[17]^{\circ} \operatorname{search}^{\circ} \operatorname{condition}^{\circ}$ and $^{\circ}$ the $^{\circ}$ results $^{\circ}$ are listed ${ }^{\circ}$ in $^{\circ}$ Table $^{\circ} 2 .^{\circ}$ For $^{\circ} 50^{\circ} \mathrm{fmol}^{\circ}{ }^{\circ} \mathrm{a}^{\circ}$ high $^{\circ}$ protein $^{\circ}$ sequence coverage of $75 \%$ was obtained with 52 matched peptide fragments. Furthermore, for 100 attomol, a protein sequence coverage of $18 \%$ was obtained with 12 peptide

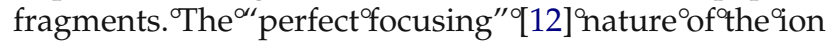
optical system contributed to a 100 attomol level sensitivity; however, the ion beam was restricted by the beam-defining slit placed before the first level of TES1.

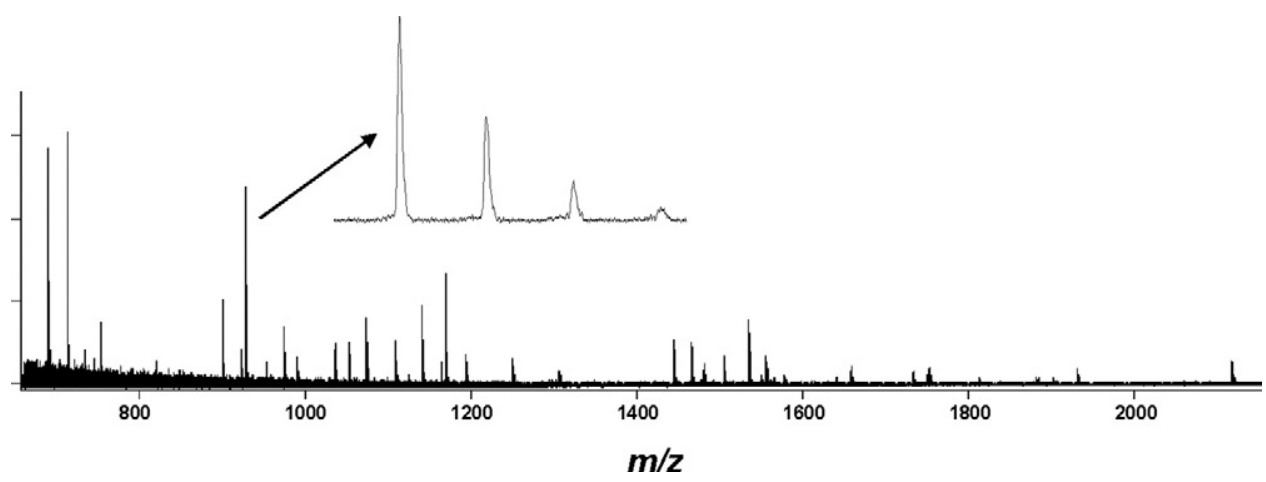

Figure 6. Typical mass spectrum observed by measuring $0.5 \mathrm{fmol}$ of a tryptic digest of BSA spotted on the MALDI plate. 


\section{Conclusions}

A novel MALDI-TOF mass spectrometer with a spiral ion trajectory was developed. We reported the major specifications of the system: (1) mass resolving power of up to 80,000 obtained at $\mathrm{m} / \mathrm{z}=2500$, (2) mass accuracy of less than 2 ppm obtained using an internal calibration method across the $\mathrm{m} / \mathrm{z}$ range of 700 to 2800 , and (3) a high sensitivity that allowed us to identify proteins by peptide mass fingerprinting down to a 100 attomol level. The results indicated that a combination of the delayed extraction technique and the spiral ion optical system could be successfully used to obtain improved mass resolving power and mass accuracy over a wide $\mathrm{m} / \mathrm{z}$ range of 500 to 3000 in the MALDI-TOF mass spectrometer.

\section{References}

1. Brown, R. S.; Lennon, J. J. Mass Resolution Improvement by Incorporation of Pulsed Ion Extraction in a Matrix-Assisted Laser Desorption/ Ionization Linear Time-of-Flight Mass Spectrometer. Anal. Chem. 1995, 67, 1998-2003.

2. Vestal, M. L.; Juhasz, P.; Martin, S. A. Delayed Extraction MatrixAssisted Laser Desorption Time-of-Flight Mass Spectrometry. Rapid Commun. Mass Spectrom. 1995, 9, 1044-1050.

3. Tanaka, K.; Ido, Y.; Akita, S.; Yoshida, Y.; Yoshida, T. Detection of High Mass Molecules by Laser Desorption Time-of-Flight Mass Spectrometry. Proceeding of the 2nd Japan-China Joint Symposium on Mass Spectrometry; Osaka, Japan, September, 1987.
4. Karas, M.; Hillenkamp, F. Laser Desorption Ionization of Proteins with Molecular Masses Exceeding 10,000 Daltons. Anal. Chem. 1988, 60, 2229-2301.

5. Stephens, W. E. A Pulsed Mass Spectrometer with Time Dispersion. Phys. Rev. 1946, 69, 691.

6. Cameron, A. E.; Eggers, D. F. An Ion "Velocitron". Rev. Sci. Instrum. 1948, 19, 605-607.

7. Juhasz, P.; Vestal, M. L.; Stephen, A. M. On the Initial Velocity of Ions Generated by Matrix-Assisted Laser Desorption Ionization and Its Effect on the Calibration of Delayed Extraction Time-of-Flight Mass Spectra. J. Am. Soc. Mass Spectrom. 1997, 8, 209-217.

8. Satoh, T; Tsuno, H.; Iwanaga, M.; Kammei, Y. The Design and Characteristic Features of a New Time-of-Flight Mass Spectrometer with a Spiral Ion Trajectory. J. Am. Soc. Mass Spectrom. 2005, 16, 1969-1975.

9. Satoh, T; Tsuno, H.; Iwanaga, M.; Kammei, Y. A New Spiral Time-ofFlight Mass Spectrometer for High Mass Analysis. J. Mass Spectrom. Soc. Jpn. 54:11 2006, 17

10. Poschenrieder, W. P. Multiple-Focusing Time-of-Flight Mass Spectrometers. Part II. TOFMS with Equal Energy Acceleration. Int. J. Mass Spectrom. Ion Phys. 1972, 6, 357-373.

11. Sakurai, T.; Nakabushi, H.; Hiasa, T.; Okanishi, K. A New MultiPassage Time-of-Flight Mass Spectrometer at JAIST. Nucl. Instrum. Methods A 1999, 427, 182-186.

12. Ishihara, M.; Toyoda, M.; Matsuo. T. Perfect Space and Time Focusing Ion Optics for Muti-Turn Time-of-Flight Mass Spectrometer. Int. J. Mass Spectrum. 2000, 197, 179-189.

13. Toyoda, M.; Ishihara, M.; Yamaguchi, S.; Ito, H.; Matsuo, T.; Reinhard, R.; Rosenbauer, H. Construction of a New Multi-Turn Time-of-Flight Mass Spectrometer. J. Mass Spectrom. 2000, 35, 163-167.

14. Okumura, D.; Toyoda, M.; Ishihara, M.; Katakuse, I. A Simple MultiTurn Time-of-Flight Mass Spectrometer "MULTUM II". J. Mass Spectom. Soc. Jpn. 51:349 2003, 353

15. Okumura, D.; Toyoda, M.; Ishihara, M.; Katakuse, I. Application of a Multi-Turn Time-of-Flight Mass Spectrometer "MULTUM II" to Organic Compounds Ionized by MALDI. J. Mass Spectrom. 2004, 39, 86-90.

16. Matsuda, H. Electrostatic Analyzer with Variable Focal Length. Rev. Sci. Instrum. 1961, 32, 850-852.

17. http://www.matrixscience.com 